\title{
The Relationship between Giant Goiter and Operative Complications: A Retrospective Study
}

\author{
Fatin R. Polat1 ${ }^{*}$, Yasin Duran1, Havva Nur Alparslan Yümün², Gülay Sariçam² \\ ${ }^{1}$ Namık Kemal University Medical Faculty, Department of Surgery, Tekirdag, Turkey \\ ${ }^{2}$ Çorlu State Hospital, Department of General Surgery, Tekirdag, Turkey \\ Email:*polat22@hotmail.com
}

How to cite this paper: Polat, F.R., Duran, Y., Yümün, H.N.A. and Sariçam, G. (2017) The Relationship between Giant Goiter and Operative Complications: A Retrospective Study. Surgical Science, 8, 299-304. https://doi.org/10.4236/ss.2017.87032

Received: June 8, 2017

Accepted: July 7, 2017

Published: July 10, 2017

Copyright $\odot 2017$ by authors and Scientific Research Publishing Inc. This work is licensed under the Creative Commons Attribution International License (CC BY 4.0).

http://creativecommons.org/licenses/by/4.0/

(c) (†) Open Access

\begin{abstract}
Background: Thyroidectomy for giant goiter is a surgical challenge due to distorted and displaced anatomy. The aim of this study is to evaluate the relationship between giant goiter and its operative complications. Material and Methods: A retrospective multicenter study of consecutive patients who had thyroid surgery was conducted, including 639 patients who undergone thyroidectomy in State hospital at Van and Corlu city-Turkey. Seven cases had giant goiter in the patients. Total thyroidectomy was performed all patients. Results: All patients were women. The mean weight of glands removed was $689 \mathrm{gr}$ in giant goiter's patients. Two operative complications had happened; right site injury of the external branch of the superior laryngeal nerve had happened to one patient; hypocalcemia was happened to another one patient. In those two patients previously were operated partial thyroidectomy. Conclusions: Thyroidectomy for a massively enlarged goiter is technically challenging. The predominant operative complications were related to previously operate and the thyroid gland due to distorted and displaced anatomy. The surgical approach to such cases requires carefully preoperative evaluation and planning. Especially, using of intraoperative nerve monitoring is to be useful in these difficult cases which previously had undergone surgery.
\end{abstract}

\section{Keywords}

Thyroidectomy, Giant Goiter, Technical Difficulties

\section{Introduction}

Goiters (from the Latin guttur, throat), defined as an enlargement of the thyroid, have been recognized since 2700 B.C. even though the thyroid gland was not documented as such until the Renaissance period [1] [2] [3]. Goiters may be 
diffuse, uninodular, or multinodular. It is estimated that goiter affects $5 \%$ of the general population [1] [2] [3]. Giant goiter is an enlargement of the thyroid gland not less than $10 \mathrm{gr} /$ kilogram body weight. The massively expanding goiter due to the strategic anatomic location of thyroid gland, in addition to being cosmetically disfiguring can seriously compromise the patency of the trachea and oesophagus [4] [5] [6] [7]. Thyroidectomy for such goiters is a surgical challenge due to distorted and displaced anatomy. The aim of this study is to evaluate the relationship between giant goiter and its operative complications.

\section{Material and Methods}

A retrospective multicenter study of consecutive patients who had thyroid surgery was conducted. Between July 1999 and December 2016, 639 patients were undergone total or subtotal thyroidectomy due to goiter in State Hospital at Van (1999-2004) and Çorlu city (2015-2016) - Turkey. All patients were living rural area. Before operation all patient was undergone ultrasound exemination. Only seven cases of the goiter were included in this retrospective study because of have a giant goiter. Malignant with giant goiter and less than 500 gr goiter were excluded. Total thyroidectomy was performed all patients who had giant goiter by the same author. The results were processed with SPSS ${ }^{\oplus}$ ver. 21.0 (Chicago IL), $\mathrm{p}<0.05$ was accepted to be statistically significant.

\section{Results}

Clinical features of patients and operative results are shown in Table 1. Mean age of the patients was 46 (range 37 to 56). All patients were women. Statistically significant differences were found between in women and man $(\mathrm{p}<0.005)$. Mean operative time was $120 \mathrm{mn}$ (range: 105 to $135 \mathrm{mn}$ ). The mean weight of glands removed was $689.57 \mathrm{gr}$ (range 600 to $820 \mathrm{gr}$ ). Blood loss was negligible in all patients but only two patients required one unit blood transfusion. Right site injury

Table 1. Patients and clinical data.

\begin{tabular}{|c|c|c|c|c|c|c|c|}
\hline Cases & 1 & 2 & 3 & 4 & 5 & 6 & 7 \\
\hline Age & 45 & 37 & 39 & 56 & 43 & 57 & 45 \\
\hline Sex & \multicolumn{7}{|c|}{ Female } \\
\hline Living area & \multicolumn{7}{|c|}{ Semi urban area } \\
\hline Duration of procedure & $125 \mathrm{mn}$ & $120 \mathrm{mn}$ & $136 \mathrm{mn}$ & $103 \mathrm{mn}$ & $135 \mathrm{mn}$ & $105 \mathrm{mn}$ & $123 \mathrm{mn}$ \\
\hline Weight of glands removed & $670 \mathrm{gr}$ & $600 \mathrm{gr}$ & $802 \mathrm{gr}$ & $625 \mathrm{gr}$ & $605 \mathrm{gr}$ & $820 \mathrm{gr}$ & $705 \mathrm{gr}$ \\
\hline Duration of neck swelling & 18 & 17 & 30 & 15 & 17 & 20 & 21 \\
\hline Complication of surgery & \multicolumn{5}{|c|}{ No complications } & lrn.sp.inj. & hypocalcm. \\
\hline Retrosternal extension & Yes & Yes & No & Yes & No & Yes & Yes \\
\hline Tracheal deformity & \multicolumn{7}{|c|}{ Yes } \\
\hline Blood transfusion & No & Yes & No & No & No & No & No \\
\hline Tracheal stenosis & \multicolumn{6}{|c|}{ Yes } & No \\
\hline Previous operation & \multicolumn{5}{|c|}{ No } & \multicolumn{2}{|c|}{ Yes } \\
\hline
\end{tabular}


of the external branch of the superior laryngeal nerve was happened one patient. Hypocalcemia was happened another one. These two patients had subtotal thyroidectomy operation previously. Statistically significant differences were found between complications and previously operated in patients $(\mathrm{p}<0.005)$. No another complication was seen in any of these patients. There was no mortality. Histologically all of them were colloid goiters.

Cases 1, 2, 3, 4, and 5: An 45, 37, 39, 56, 43 years' old women presented with a massively enlarged goiter of more than 18, 30, 15, 17, 20 years duration (Table 1). The thyroid was asymmetrically enlarged and has a smooth surface without areas of encapsulation, irreguler scarring and positive Pemberton's sign. Thyroid function tests; free $T_{3}$ and $T_{4}$ were within normal limits, but thyroid stimulate hormone (TSH) levels were high. The patients had substernal extension on the ultrasound examination. After an informed consent total thyroidectomy was performed to the patients. Any complications were not seen. All patients were discharged on the 2nd or 3rd postoperative day. Weight of removed thyroid gland was $670,600,802,625,605$ gr. Lifelong $\mathrm{T}_{4}$ therapy was recommended.

Case 6: A 57-year-old woman presented with a massively enlarged goiter of more than 10 years duration. She had history of partial thyroidectomy 16 years ago. The thyroid was symmetrically enlarged and has a smooth surface without areas of encapsulation, irregular scarring and positive Pemberton's sign. Thyroid function test; free $\mathrm{T}_{3}$ and $\mathrm{T}_{4}$ were within normal limits, but TSH level was high. The patient had substernal extension on the ultrasound examination. Total thyroidectomy was performed. Injury to right site of the external branch of the superior laryngeal nerve was happened. The patient discharged on the 4'th postoperative day. Weight of removed thyroid gland was $820 \mathrm{gr}$ (Figure 1(a), Figure 1(b)). Lifelong $\mathrm{T}_{4}$ therapy was recommended.

Case 7: A 45-year-old woman presented with a massively enlarged goiter of more than 9 years duration. She had history of partial thyroidectomy 12 years ago. The thyroid is symmetrically enlarged and has a smooth surface without areas of encapsulation, irregular scarring and positive Pemberton's sign. She had recent history of exertional stridor and neck discomfort. Thyroid function tests; free $\mathrm{T}_{3}$ and $\mathrm{T}_{4}$ were within normal limits, but TSH level was high. The patient had substernal extension on the ultrasound examination. Total thyroidectomy was performed. Hypocalcemia was happened and the patient discharged on the 4th postoperative day. Weight of removed thyroid gland was $705 \mathrm{gr}$ (Figure 2(a), Figure 2(b)). Lifelong $\mathrm{T}_{4}$ therapy was recommened.

\section{Discussion}

Simple goiter may be physiologic, occurring during puberty or the menses or during pregnancy; or it may occur in patients from endemic (iodine-poor) regions or as a result of prolonged exposure to goitrogenic foods or drugs [1] [2] [3] [4] [5]. It is usually seen in women. All the cases were women in this study. Goiters may be diffuse, uninodular, or multinodular. Most nontoxic goiters constituting the commonest type of thyroid gland disease are thought to result from 


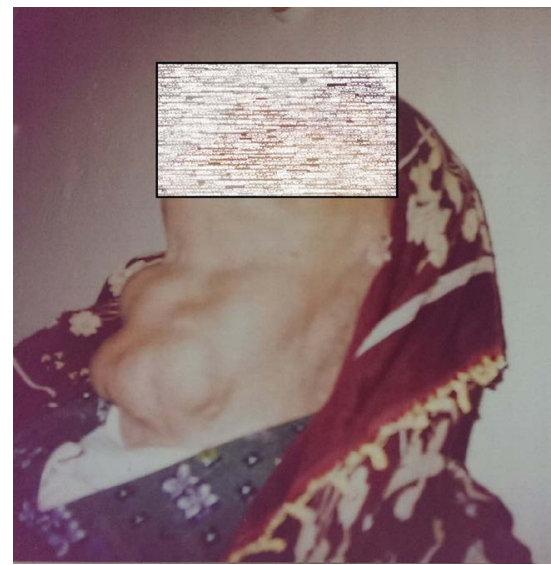

(a)

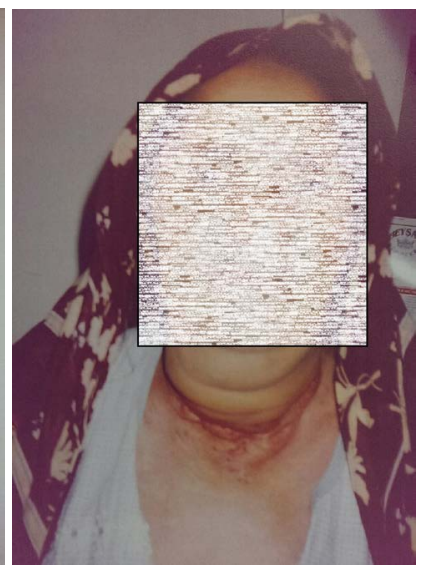

(b)

Figure 1. (a), (b) In this case, right site injury of the superior laryngeal nevre.

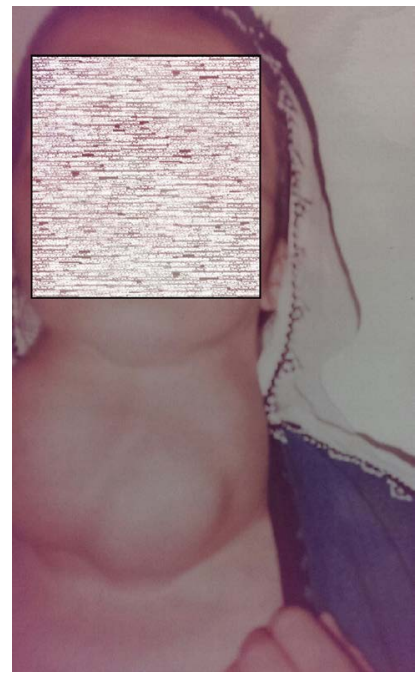

(a)

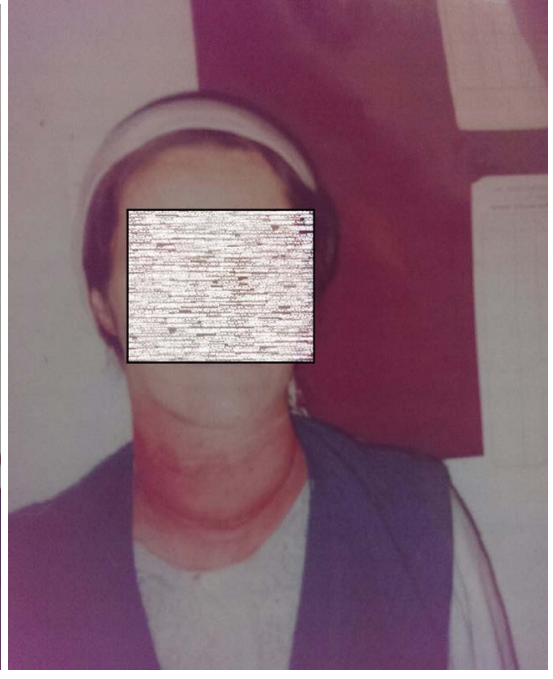

(b)

Figure 2. (a), (b) In this case, hypocalcemia was happened.

TSH stimulation secondary to inadequate thyroid hormone synthesis [6] [7] [8] [9]. The patients often complain of a pressure sensation in the neck. As the goiters become very large, compressive symptoms such as dyspnea and dysphagia ensue. Patients also describe having to clear their throats frequently [2].

Computerized tomography scan and ultrasound are useful imaging modality especially in complicated massive goiter, in delineating the degree of tracheal compression and deviation and establishing the extent of retrosternal extension [2] [10]-[15].

Most euthyroid patients with small, diffuse goiters do not require treatment [2]. The patients with large goiters; using exogenous thyroid hormone to reduce the TSH stimulation of gland growth; this treatment may result in decrease and/ or stabilization of goiter size and is most effective for small diffuse goiters [2]. Endemic goiters are treated by iodine administration [1] [2] [3] [4]. Surgical re- 
section is reserved for goiters that; continue to increase despite $\mathrm{T}_{4}$ suppression, cause obstructive symptoms, have substernal extension, have malignancy suspected, and are cosmetically unacceptable. Nearly total or total thyroidectomy is the treatment of choice [2]. All the patients had substernal extension, and were undergone total thyroidectomy.

Treatment of large goiters is generally surgery. Total thyroidectomy is performed surgically [7]. The most important advantage of thyroid surgery for massively enlarged goiter being its immediate effect and complete resolution of obstructive symptoms [7]. Given an accomplished surgeon and good preoperative preparation, injuries to the recurrent laryngeal nerves and parathyroid glands occur in less than $2 \%$ of cases [7] [8] [9]. Adequate exposure and avoidance of injury to the recurrent laryngeal nerves and parathyroid glands are essential. The predominant operative complications were related to previously operated, the thyroid gland due to distorted and displaced anatomy. Moreover surgery for recurrent goiter carries a 10 fold higher complication rate with complications such as permanent hypoparathyroidism (3.4\%), the external branch of the superior laryngeal nevre palsy (20\%) and recurrent laryngeal nerve palsy (8\%) [15] [16] [17]. Two complications were happened in this study. Right site injury of the external branch of the superior laryngeal nerve was happened the one patient. By that time, nerve monitoring wasn't used during thyroid surgery. Hypocalcemia was happened another one. In the two patients previously were undergone surgeries (subtotal thyroidectomy).

\section{Conclusion}

Thyroidectomy for a massively enlarged goiter is technically challenging. The surgical approach to such cases requires careful preoperative evaluation and planning. Especially using of intraoperative nerve monitoring may be prevented as nevre injury complication in these difficult cases that previously had undergone surgery. Adequate exposure and avoidance of injury to the recurrent laryngeal nerves and parathyroid glands are essential.

\section{Acknowledgements}

This scientific paper was presented at the 20th National Surgery Congress 2016 Antalya Turkey.

\section{Conflict of Interest}

The author has no conflict of interest to declare.

\section{References}

[1] Day, T.A., Chu, A. and Hoang, K.G. (2003) Multinodular Goiter. Otolaryngologic Clinics of North America, 36, 35-54. https://doi.org/10.1016/S0030-6665(02)00157-3

[2] Lal, G. and Orlo H. (2010) Clark, Thyroid, Parathyroid, and Adrenal Diseases. In: Schwartz, S.I., Ed., Principles of Surgery, 7th Edition, McGraw-Hill International Inc., New York, 1520-1590. 
[3] Thomas, H.O. (1959) The Large Goitres. West African Journal of Medicine, 8, 8586.

[4] Dere, K., Teksoz, E., Sen, H., Orhan, M.E., et al. (2008) Anaesthesia in a Child with Massive Thyroid Enlargement. Paediatric Anaesthesia, 18, 797-798. https://doi.org/10.1111/j.1460-9592.2008.02547.x

[5] Irfan, M., Jiham, W.S. and Shahid, H. (2010) Massive Goiter with Retrosternal Extension Encasing Trachea and Oesophagus. Medical Journal of Malaysia, 65, 85-86.

[6] Hodges, A.M. (2005) Excision of a $1.9 \mathrm{Kg}$ Goitre under Local Anaesthetic. Tropical Doctor, 35, 43-44. https://doi.org/10.1258/0049475053001877

[7] Harjit, K.D. and Hisham, A.N. (2005) Large Fungating Thyroid Cancers. A Unique Surgical Challenge. Asian Journal of Surgery, 28, 48-51. https://doi.org/10.1016/S1015-9584(09)60259-1

[8] Machado, N.O. (2011) Thyroidectomy for Massive Goiter Weighing More Than 500 Grams. Technical Difficulties, Complications and Management. Review. Surgical Science, 2, 278-284. https://doi.org/10.4236/ss.2011.25060

[9] Rahman, G.A. and Mamudu, N.A. (2014) Thyroidectomy under Local Anaesthesia: Experience. Sajaa, 10, 29-30.

[10] Hodges, A.M. (2005) Excision of a 1.9 Kg Goitre under Local Anaesthetic. Tropical Doctor, 35, 43. https://doi.org/10.1258/0049475053001877

[11] Dralle, H., Sekulla, C., Lorenz, K., Brauckhoff, M., et al. (2008) German IONM Study Group. Intraoperative Monitoring of the Recurrent Laryngeal Nerve in Thyroid Surgery. World Journal of Surgery, 32, 1358-1366. https://doi.org/10.1007/s00268-008-9483-2

[12] Green, W.E., Shepperd, W.H., Stevensen H.M. and Wilson, W. (1979) Tracheal Collapse after Thyroidectomy. British Journal of Surgery, 66, 554-557. https://doi.org/10.1002/bjs.1800660811

[13] Sinha, P.K., Dubey, P.K. and Singh, S. (2000) Identifying Tracheomalacia. British Journal of Anaesthesia, 84, 127-128. https://doi.org/10.1093/oxfordjournals.bja.a013372

[14] Palazzo, F.F., Allen, J.G., Greatorex, R.A. (2000) Laryngeal Mask Airway and the Fibre-Optic Tracheal Inspec-tion in Thyroid Surgery: A Method for Timely Identification of Tracheomalacia Requiring Tracheostomy. Annals of The Royal College of Surgeons of England, 82, 141-142.

[15] Machado, N.O., Grant, C.S., Sharma, A.K. and Al Sabi., H.A. (2011) Large Posterior Mediastinal Retrosternal Goiter Managed by Transcervical and Lateral Thorocotomy Approach. General Thoracic and Cardiovascular Surgery, 59, 507-511. https://doi.org/10.1007/s11748-010-0712-x

[16] ElBashier, E.M., Hassan Widtalla, A.B. and ElMakki Ahmed, M. (2008) Tracheostomy with Thyroidectomy: Indications, Management and Outcome: A Prospective Study. International Journal of Surgery, 6, 147-150. https://doi.org/10.1016/j.ijsu.2008.01.010

[17] Jansson, S. and Tisell, L.E. (1998) Partial Superior Laryngeal Nerve Lesions before and after Thyroid Surgery. World Journal of Surgery, 12, 526. 
Submit or recommend next manuscript to SCIRP and we will provide best service for you:

Accepting pre-submission inquiries through Email, Facebook, LinkedIn, Twitter, etc. A wide selection of journals (inclusive of 9 subjects, more than 200 journals)

Providing 24-hour high-quality service

User-friendly online submission system

Fair and swift peer-review system

Efficient typesetting and proofreading procedure

Display of the result of downloads and visits, as well as the number of cited articles Maximum dissemination of your research work

Submit your manuscript at: http://papersubmission.scirp.org/

Or contact ss@scirp.org 